\title{
Dr. Charles G. Drake 1920 - 1998
}

\author{
Gary G. Ferguson and Vladimir C. Hachinski
}

Charles George Drake has passed into legend, to join the pantheon of the greatest neurosurgeons of all time. Such a fate could not have been foretold when he was born in Windsor, Ontario on the 21st of July 1920, two months after his father had died of Spanish influenza. At the age of 18 , he entered the University of Western Ontario and graduated in Medicine in 1944. He was a junior rotating intern at the Toronto General Hospital in 1944-45 and then returned to Western, completing a Master of Science degree in neurophysiology. He spent a year with John Fulton at Yale, where he studied the motor physiology of the anterior cerebellum. After two years of surgical training at Victoria Hospital in London, Ontario, he returned to the Toronto General Hospital to train with Canada's great pioneering neurosurgeon, Dr. Kenneth McKenzie. McKenzie sparked Drake's interest in the surgery of intracranial aneurysms in what was certainly one of the earliest such operations in Canada. On inadvertently encountering a ruptured aneurysm during an emergency procedure for an intracerebral hematoma, Drake inquired of his mentor as to what he should do. The response, "Well, Charlie, you had better clip it."

Later, Drake visited the great names in neurology and neurosurgery in Europe including Sir Hugh Cairns in Oxford. In 1952, he returned to London, Ontario where he became the first neurosurgeon in the region. He took a great interest in the development of aneurysm surgery, and in particular, those most difficult aneurysms of the basilar artery and posterior circulation. He demonstrated exceptional resourcefulness and tenacity in dealing with these lesions, learning from every case. He recognized the need for a multi-disciplinary approach working closely with Ronald Aitken, a pioneering Canadian neuroanaesthetist, and John Allcock, a renowned neuroradiologist. Soon, Drake became the world's foremost aneurysm neurosurgeon, operating on the rich and famous, and the poor and humble, from television star Della Reese to a child sent by Mother Theresa.

He foresaw the advantages of bringing together neurosurgery, neurology and all of the disciplines dealing with the brain in one department. He did this with his great friend, Dr. Henry Barnett, by becoming the first Chairman of the Department of Clinical Neurological Sciences at the University of Western Ontario (19691974). They put London on the international map. He was the Chairman of the Department of Surgery at the University of Western Ontario from 1974-1984. He was President of the Royal College of Physicians and Surgeons of Canada (1971-1973), of the American Association of Neurological Surgeons (1977), the World Federation of Neurosurgical Societies (1977-1981) and the American College of Surgeons (1984-1985). He chaired the editorial board of The Journal of Neurosurgery (1975-1976) and was a member of the editorial board of several scientific journals. He authored or co-authored more than 100 scientific publications, culminating in a classic monograph on "Surgery of Vertebrobasilar Aneurysms - London, Ontario Experience on 1767 Patients" with S.J. Peerless and J.A. Hernesniemi in 1996.

Drake combined extraordinary talent with a common touch. He stressed his errors as lessons, and strove to make fewer all his life. He fished, hunted, and piloted his own aeroplane. He golfed with

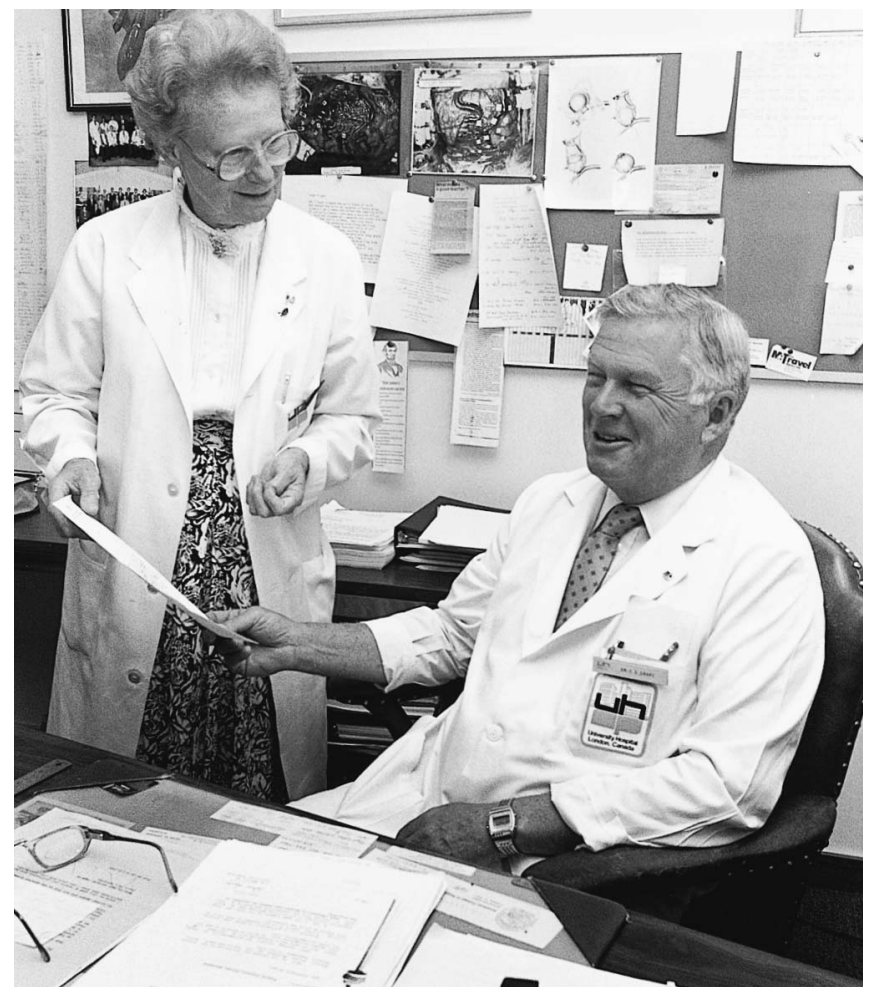

Dr. Drake with his secretary, Dorothy McManus

characteristic concentration and success, scoring three holes-in-one in his lifetime. Charlie gloried in his marriage to his beloved wife, Ruthie, and their family of four sons and 14 grandchildren.

Drake was the recipient of many job offers outside of Canada, which he resisted, remaining faithful to his country and the many opportunities that it provides its citizens. He was the recipient of many honours and awards, among which, investiture in the Order of Canada touched him the most. On August 19, 1998, slightly less than one month before his death on September 15, 1998, Drake received the highest honour that Canada can bestow on a citizen, when he was elevated from Officer to Companion of the Order of Canada in recognition of his service to Canada and to humanity at a special ceremony in London, Ontario presided over by Hillary Weston, the Lieutenant Governor of Ontario. In spite of his fame as one of the greatest surgeons of his age, nothing shook his conviction that he was "just a simple surgeon poking at the edges of knowledge". To the day before he died, he was reviewing angiograms on challenging patients and giving advice to younger colleagues. To the end, he maintained a particular interest in young people. Accordingly, the Resident's Research Day of the Department of Clinical Neurological Sciences will be named in his honour and a Distinguished Visiting Professorship in Neurosurgery at the University of Western Ontario has been established in his name. His life and work were an inspiration to everyone who had the privilege to know him. 